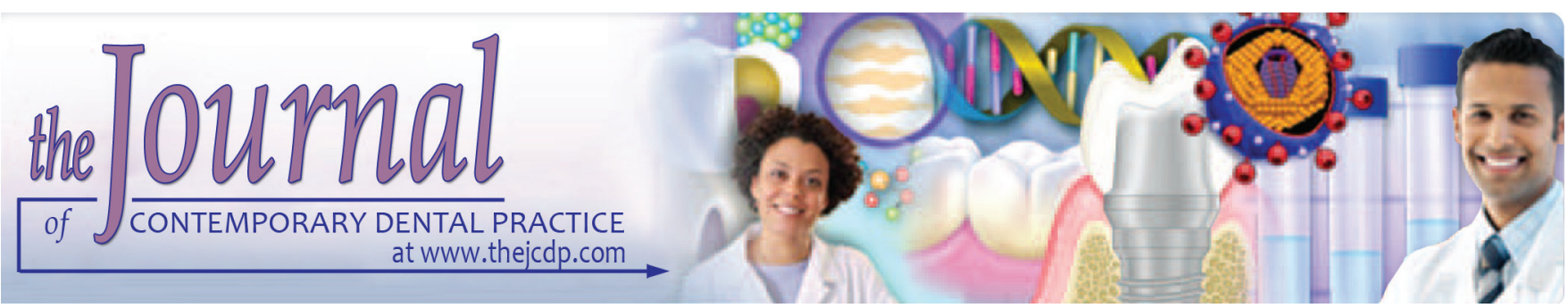

\title{
Risk Assessment in Long-term Survival Rates of Dental Implants: A Prospective Clinical Study
}

\author{
${ }^{1}$ Rinkee Mohanty, ${ }^{2}$ Punkit S Sudan, ${ }^{3}$ Anand M Dharamsi, ${ }^{4}$ Rizwan Mokashi, ${ }^{5}$ Archana L Misurya, ${ }^{6}$ Pradeepta Kaushal
}

\begin{abstract}
Aim: The present study was done to analyze the risk factors associated with dental implants in its survival rate.

Materials and methods: The present study was conducted on 208 patients with 425 dental implants placed. Patients were divided into four groups: group I (diabetes), group II (periodontitis), group III (smoking), and group IV (bruxism). All patients were followed for 8 to 10 years for the survival rates.
\end{abstract}

Results: Out of 425 dental implants, 145 were inserted in 72 males and 280 in 136 females. The difference was significant $(p=0.01)$. Group I had 16 males and 36 females, group II had 20 males and 32 females, group III had 28 males and 24 females, and group IV had 8 males and 44 females. The difference was statistically significant $(p<0.05)$. Out of 425 implants, $90(21.17 \%)$ had failures: 24 dental implants $(29 \%)$ in group I, 22 dental implants (15.2\%) group II, 34 dental implants (27\%) in group III, and 10 dental implants (13\%) in group IV showed failure. The difference was significant $(p<0.05)$. Success rate was $70.7 \%$ in group I, $83.3 \%$ in group II, $80.9 \%$ in group III, and $86.3 \%$ in group IV. The difference was nonsignificant $(p>0.05)$.

Conclusion: Diabetes, periodontitis, bruxism, and smoking are among various causative factors which affect the survival rate of dental implants. These are risk factors leading to implant failures.

\footnotetext{
${ }^{1}$ Department of Periodontics \& Oral Implantology, Institute of Dental Sciences, Siksha 'O'Anusandhan University, Bhubaneswar Odisha, India

${ }^{2}$ Department of Prosthodontics, Cradley Health, Birmingham West Midlands, USA

${ }^{3}$ Department of Periodontics, R.R. Dental College \& Hospital Udaipur, Rajasthan, India

${ }^{4}$ Department of Conservative Dentistry and Endodontics S.M.B.T. Dental College \& Hospital, Nashik, Maharashtra, India

${ }^{5}$ Department of Oral Pathology, Maharana Pratap College of Dentistry \& Research Centre, Gwalior, Madhya Pradesh, India

${ }^{6}$ Department of Prosthodontics, College of Dental Science \& Hospital, Indore, Madhya Pradesh, India
}

Corresponding Author: Rinkee Mohanty, Department of Periodontics \& Oral Implantology, Institute of Dental Sciences Siksha 'O' Anusandhan University, Bhubaneswar, Odisha, India e-mail: rinkeemohanty@gmail.com
Clinical significance: Diabetes, periodontitis, bruxism, and smoking are among various causative factors which affect the survival rate of dental implants.

Keywords: Bruxism, Dental implant, Periodontitis, Smoking.

How to cite this article: Mohanty R, Sudan PS, Dharamsi AM, Mokashi R, Misurya AL, Kaushal P. Risk Assessment in Longterm Survival Rates of Dental Implants: A Prospective Clinical Study. J Contemp Dent Pract 2018;19(5):587-590.

\section{Source of support: Nil}

Conflict of interest: None

\section{INTRODUCTION}

The management of missing teeth is replacement with either removable partial denture (RPD), fixed partial denture (FPD), or dental implants. For missing of one or few teeth, RPD was considered best treatment modality. The low cost made it popular among people. However, the presence of clasps with it poses difficulty as it may impinge on soft tissue leading to trauma. ${ }^{1}$ Excessive pressure of the clasp may cause mobility and abrasion of adjacent teeth. In terms of higher success rate, FPD replaced RPD. It eliminated the need of clasps. It lacks the acrylic part, hence, has no contact with gingiva. The only drawback with it was that for replacing single tooth, there was need of taking support from adjacent teeth. Teeth anterior and posterior to missing teeth required crown preparation by cutting it in all dimensions. Patient frequently complained of postoperative sensitivity. $^{2}$

Dental implants have been used in dentistry for the past few years. It is considered suitable for single edentulous area. It provides better long-lasting results. There was no hypersensitivity as there was no tooth reduction as in case of FPD. Dental implants are directly placed in the bone which gets attached to it via osteointegration. Even with higher cost of dental implant, it is still the preferred options among patients. ${ }^{3}$ 
The insertion of dental implant is a technique-sensitive process. The success rate is determined by the factors, such as proper osteointegration, absence of peri-implantitis, etc. Dental implant insertion following standardized technical steps leads to long-term survival rate. However, factors, such as age, gender, bone quality, type and design of dental implant, general health of the patient, medical status of the patient, history of diabetes, smoking are various factors affecting the outcome of the treatment modality. Proper meticulous oral hygiene and timely follow-ups also determine the success rates. ${ }^{4}$ The present study was aimed at determining the risk factors associated with dental implants survival rate.

\section{MATERIALS AND METHODS}

The present study was conducted on 208 patients of both genders. It included 425 dental implants placed in both arches. All patients were followed for 8 to 10 years. All patients were informed regarding the study and written consent was obtained. Ethical clearance was taken prior to the study from the Institutional Ethics Committee.

General information, such as name, age, gender, etc., were recorded. Patients with history of smoking, diabetes, periodontitis, and bruxism were included in the study. Pregnant and medically compromised patients were excluded from the study. All were divided into four groups. Group I was diabetes group comprising 52 patients, group II was periodontitis group of 52 patients, group III was smoking group consisting of 52 patients, and group IV was bruxism group comprising 52 patients. Patients were evaluated clinically to see implant loss, mobility, bone loss, and radiographically for the presence of peri-implantitis. Results thus obtained were subjected to statistical analysis using chi-square test; $\mathrm{p}$-value $<0.05$ was considered significant.

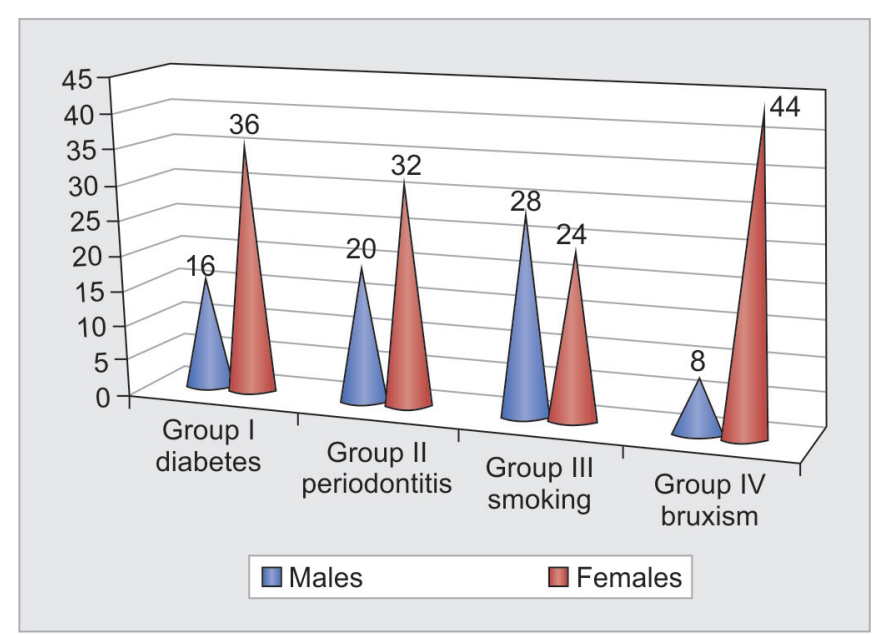

Graph 1: Distribution in different groups
Table 1: Distribution of patients

\begin{tabular}{lllll}
\hline Gender & Males & Females & Total & $p$-value \\
\hline Number & 72 & 136 & 208 & 0.05 \\
No. of implants & 145 & 280 & 425 & 0.01 \\
\hline$p>0.01$
\end{tabular}

$p>0.01$

\section{RESULTS}

Out of 208 patients, 72 were males and 136 females (Table 1 ). The difference was significant ( $p=0.05$ ). Out of 425 dental implants, 145 were inserted in males and 280 in females. The difference was significant $(p=0.01)$. Graph 1 shows that group I was diabetes group (males: 16, females: 36), group II was periodontitis group (males: 20, females: 32 ), group III was smoking group (males: 28, females: 24), and group IV was bruxism group (males: 8 , females: 44 ). The difference was statistically significant $(\mathrm{p}<0.05)$. Out of 425 implants, $90(21.17 \%)$ had failures. In group I, out of 82 implants, 24 (29\%) showed failures, in group II, out of 144 implants, $22(15.2 \%)$ showed failures, in group III, out of 126 implants, 34 (27\%) showed failures and in group IV, out of 73 implants, $10(13 \%)$ showed failures. The difference was significant $(p<0.05)($ Graph 2$)$. Overall success rate was $78.9 \%$. Maximum survival rate was seen in group IV $(86.3 \%)$ followed by group II $(83.3 \%)$, group III $(80.9 \%)$, and group I $(70.7 \%)$. The difference was nonsignificant $(p>0.05)$ (Graph 3).

\section{DISCUSSION}

Dental implants have been gaining importance in the field of dentistry. The implant insertion in missing teeth has become choice of both patients and dentists. Though it is nowadays considered preferred management for edentulous area, complications and failures are not uncommon. Esposito et $\mathrm{al}^{5}$ in their study of biological factors contributing to failures of osseointegrated oral implants

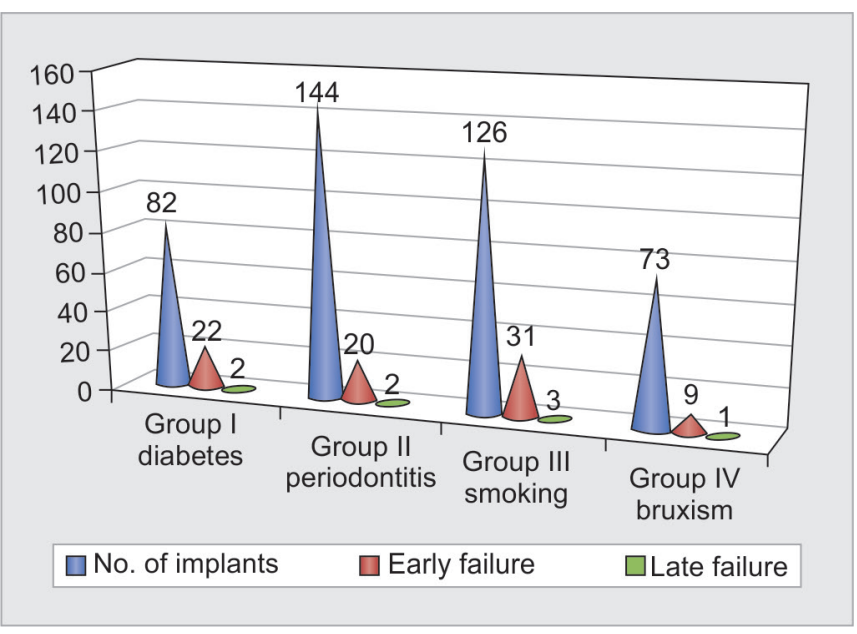

Graph 2: Dental implant failures in all groups 


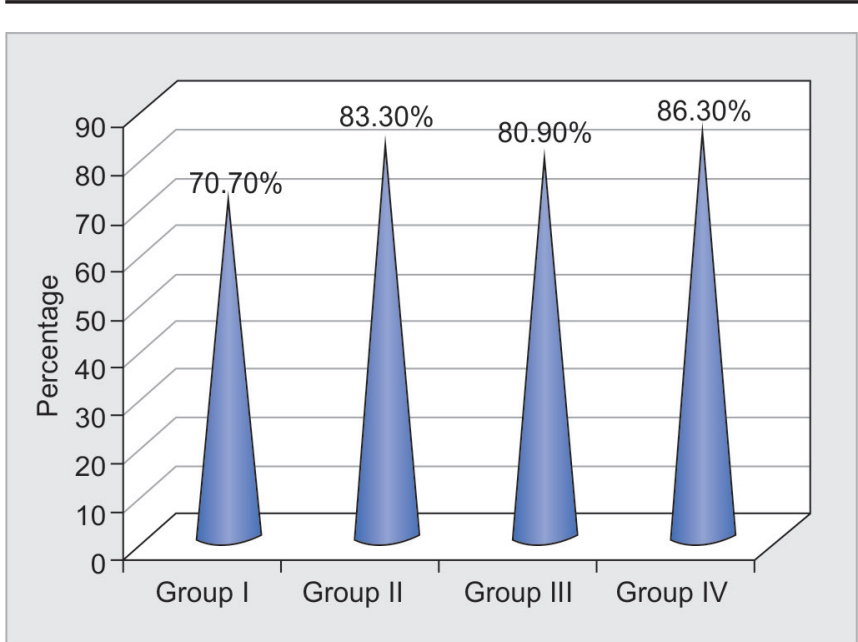

Graph 3: Success/survival rate in all groups

classified failures into early and late. Early failures are due to errors in osseointegration between implant and underlying bone. Factors, such as gender, age, smoking, etc., play important role, whereas late failures are due to peri-implantitits. Factors, such as smoking, diabetes, etc., have major role.

In this study, out of 208 patients, males were 72 and females were 136 . Out of 425 dental implants, 145 were inserted in males and 280 in females. Shenoff et $\mathrm{al}^{6}$ in their study assessed 178 dental implants in 89 type II diabetic and concluded that type II diabetic patients can be considered for dental implant therapy. Similarly, a study by Kandasamy et $\mathrm{al}^{7}$ analyzed 200 patients (males: 88, females: 112) in which 650 dental implants were inserted. Jung et $\mathrm{al}^{8}$ evaluated success rate of 6,385 dental implants inserted in 3,755 patients over 9 years.

In this study, we classified patients into four groups. Group I was diabetes group, group II was periodontitis group, group III was smoking group, and group IV was bruxism group. Each group had 52 patients. A study by Kandasamy et $\mathrm{al}^{7}$ classified patients into group I (smoking), group II (bruxism), group III (periodontal disease), group IV (diabetes), group V (bone augmentation), and group VI (bone height group). Albrektsson et $\mathrm{al}^{9}$ in their research concluded that an implant without peri-implant radiolucency, without mobility, bone loss $<0.2 \mathrm{~mm}$ per year after the first year of loading, absence of pain, and infection are signs of success rate.

In this study, we found 90 dental implants $(21.17 \%)$ had failures. In group I, the failure rate was $29 \%$. The success rate found to be $70.7 \%$. A study by Loo et $\mathrm{al}^{10}$ evaluated 255 dental implants in 138 diabetic patients and found only second-degree mobility 90 days following surgery as compared with 46 dental implants in control group. The difference of mobility in both groups was nonsignificant. Diabetes is a multiorgan metabolic disease characterized by excessive blood glucose level due to either lack of insulin or failure of body to respond to insulin receptors. Diabetes leads to poor healing and excessive tooth loss. Dowell et $\mathrm{al}^{11}$ in their study determined the success rate of dental implants: 30 implants in 20 patients with type II diabetes mellitus. Authors found three complications in patients with glycated hemoglobin level between 7.4 and 8.3. They concluded that in controlled diabetes, there was no significantly higher risk of complications as compared with normal individuals. Olson et $\mathrm{al}^{12}$ assessed the success rate of two-stage endosseous root-form implants (three different implant systems) placed in the mandibular symphysis of 89 male type II diabetic subjects in year 2000 and found $14 \%$ of dental implant failures inserted in 40 patients over 4 years and no statistically significant difference in failure rates between the three different implant systems used.

Periodontitis is the inflammatory disease characterized by excessive bone loss, tooth mobility, pockets formation, and bleeding gums. It is due to cytokines released in response to bacteria. Karoussis et $\mathrm{al}^{13}$ analyzed the survival rate of implants in control group and treated periodontitis group. They did not find significant difference in survival rate in both groups. However, the probing depth was higher in treated periodontitis group as compared with healthy individuals. Quirynen et $\mathrm{al}^{14}$ evaluated the effect of supportive periodontal therapy and implant surface roughness on implant outcome in patients with a history of periodontitis and found that patients who received periodontal therapy in the past had lower implant failure rates. Mengel et $\mathrm{ll}^{15}$ assessed bone loss in 14 patients with 41 implants. Author found average of $1.29 \mathrm{~mm}$ bone loss over 3 years follow-up period. De Boever et $\mathrm{al}^{16}$ found $0.17 \mathrm{~mm}$ bone loss in mesial and distal surfaces of 59 implants and reported $84.8 \%$ survival rates. We found that there was $15.2 \%$ failure rate in group II. The success rate was $83.3 \%$.

In this study, group III showed $27 \%$ failure. HeitzMayfield and Huynh-Ba ${ }^{17}$ in their study assessed periodontitis and smoking as risks for implant therapy and suggested that smoking is the biggest contributing factors leading to implant failure. Similarly, Klokkevold and $\mathrm{Han}^{18}$ in their study concluded that smoking, diabetes, and periodontitis affect outcomes of implant treatment. They found that impaired neutrophil level, altered oxygen supply, and decreased blood flow to tissues are due to excessive smoking, which in turns affects the survival rate of implant. Bain and $\mathrm{Moy}^{19}$ conducted a retrospective study on smokers and nonsmokers and found success rate of 88.72 and $95.23 \%$ respectively. We found $80.9 \%$ of success rate.

We found $13 \%$ failures in group IV. Bruxism is a parafunctional condition characterized by night grinding of 
teeth. This leads to severe attrition of all teeth along with patients that may manifest with temporomandibular joint pain, clicking sound, limited, and painful mouth opening. Patient often feels muscular pain. Studies have suggested the role of anxiety, stress, and incomplete sleep as contributing factors. Hartshorne ${ }^{20}$ in his study found biological and technical complications in bruxism subjects as compared with nonbruxism subjects and concluded it one of the leading causes of implant failure. We found $86.3 \%$ success rate in patients with bruxism.

\section{CONCLUSION}

Dental implants are quite common in today's life. The successful implant leads to patient as well as dentist satisfaction. However, risk factors, such as diabetes, periodontitis, bruxism, and smoking have deleterious effects on survival rate of dental implants. Counseling the diabetic patients regarding the habits and oral hygiene is necessary to improve the success rates of implants.

\section{REFERENCES}

1. Schnitman PA, Shulman LB. Recommendations of the consensus development conference on dental implants. J Am Dent Assoc 1979 Mar;98(3):373-377.

2. Heitz-Mayfield LJ. Peri-implant diseases: diagnosis and risk indicators. J Clin Periodontol 2008 Sep;35(8 Suppl):292-304.

3. Ricci G, Ricci A, Ricci C. Save the natural tooth or place an implant? Three periodontal decisional criteria to perform a correct therapy. Int J Periodontics Restorative Dent 2011 Feb;31(1):29-37.

4. Karabucak B, Setzer F. Criteria for the ideal treatment option for failed endodontics: surgical or nonsurgical? Compend Contin Educ Dent 2007 Jun;28(6)304-310.

5. Esposito M, Hirsch JM, Lekholm U, Thomsen P. Biological factors contributing to failures of osseointegrated oral implants (II). Etiopathogenesis. Eur J Oral Sci 1998 Jun;106(3):721-764.

6. Shenoff AF, Colwell JA, Bingham SF. Implants for type II diabetic patients: interim report VA implants in diabetic study group. Implant Dent 1994 Fall;3(3):183-185.

7. Kandasamy B, Kaur N, Tomar GK, Bharadwaj A, Manual L, Chauhan M. Long-term retrospective study based on implant success rate in patients with risk factor: 15-year follow-up. J Contemp Dent Pract 2018 Jan;19(1):90-93.
8. Jung RE, Pjetursson BE, Glauser R, Zembic A, Zwahlen M, Lang NP. A systematic review of the 5-year survival and complication rates of implant-supported single crowns. Clin Oral Implants Res 2008 Feb;19(2):119-130.

9. Albrektsson T, Zarb G, Worthington P, Eriksson AR. The longterm efficacy of currently used dental implants: a review and proposed criteria of success. Int J Oral Maxillofac Implants 1986;1(1):11-25.

10. Loo WT, Jin LJ, Cheung MN, Wang M. The impact of diabetes on the success of dental implants and periodontal healing. Afr J Biotechnol 2009 Oct;8(19):5122-5127.

11. Dowell S, Oates TW, Robinson M. Implant success in people with type 2 diabetes mellitus with varying glycemic control: a pilot study. J Am Dent Assoc 2007 Mar;138(3):355-361.

12. Olson JW, Shernoff AF, Tarlow JL, Colwell JA, Scheetz JP, Bingham SF. Dental endosseous implant assessments in a type 2 diabetic population: a prospective study. Int J Oral Maxillofac Implants 2000 Nov-Dec;15(6):811-818.

13. Karoussis IK, Kotsovilis S, Fourmousis I. A comprehensive and critical review of dental implant prognosis in periodontally compromised partially edentulous patients. Clin Oral Implants Res 2007 Dec;18(6):669-679.

14. Quirynen M, Vogels R, Peeters W, van Steenberghe D, Naert I, Haffajee A. Dynamics of initial subgingival colonization of 'pristine' peri-implant pockets. Clin Oral Implants Res 2006 Feb;17(1):25-37.

15. Mengel R, Kreuzer G, Lehmann KM, Flores-de-Jacoby L. A telescopic crown concept for the restoration of partially edentulous patients with aggressive generalized periodontitis: a 3-year prospective longitudinal study. Int J Periodontics Restorative Dent 2007 Jun;27(3):231-239.

16. De Boever AL, Quirynen M, Coucke W, Theuniers G, De Boever JA. Clinical and radiographic study of implant treatment outcome in periodontally susceptible and nonsusceptible patients: a prospective long-term study. Clin Oral Implants Res 2009 Dec;20(12):1341-1350.

17. Heitz-Mayfield LJ, Huynh-Ba G. History of treated periodontitis and smoking as risks for implant therapy. Int J Oral Maxillofac Implants 2009;24(Suppl):39-68.

18. Klokkevold PR, Han TJ. How does smoking, diabetes, and periodontitis affect outcomes of implant treatment. Int J Oral Maxillofac Implants 2007;22(Suppl):173-202.

19. Bain CA, Moy PK. The association between the failure of dental implants and cigarette smoking. Int J Oral Maxillofac Implants 1993 Jun;8(6):609-615.

20. Hartshorne J. Does bruxism contribute to dental implant failure? Int Dent 2015 Mar;5(3):38-42. 